\title{
Gynecological Tumor Images using HDlive US
}

\author{
${ }^{1}$ Fernando Bonilla-Musoles, ${ }^{2}$ Francisco Raga, ${ }^{3}$ Francisco Bonilla Jr, ${ }^{4}$ Juan Carlos Castillo \\ ${ }^{5}$ Luiz Eduardo Machado, ${ }^{6}$ Oscar Caballero Luna
}

\section{ABSTRACT}

Abdominal and/or vaginal two dimensional (2D) and threedimensional (3D) ultrasound (US) are the 'gold standard' technology on which diagnosis and control of gynecological tumors depend.

In recent years, a series of software that initially generated enormous interest, have been introduced to improve 2D/3D US image quality and diagnostic accuracy. Many of them have shown limited interests.

The last one and the most interesting is HDlive which incorporates a movable virtual adjustable light that, as it penetrates, produces selective illumination with respective shadows that result from the structures where light is reflected. This combination of lights and shadows results in spectacular images which are much more real than those obtained with conventional $3 D$ US.

This note simply pretends to show the quality of images obtained in cases of gynecological tumors using this easy-tohandle high definition ultrasound technology.

Keywords: Adenocarcinoma, Endometriosis, Hiperplasia, 3D HDlive US, Gynecological tumors, Ovarian tumors, Uterine polyp.

How to cite this article: Bonilla-Musoles F, Raga F, Bonilla F Jr, Castillo JC, Machado LE, Luna OC. Gynecological Tumor Images using HDlive US. Donald School J Ultrasound Obstet Gynecol 2015;9(2):149-158.

\section{Source of support: Nil}

Conflict of interest: None

\section{INTRODUCTION}

Vaginal two-dimensional (2D) ultrasound (US) is the gold standard technology on which diagnosis, control and management in gynecological tumors is based.

${ }^{1}$ Professor and Chairman, ${ }^{2,3,6}$ Assistant Professor, ${ }^{4} \mathrm{PhD}$, ${ }^{5}$ Professor

${ }^{1-3}$ Department of Obstetrics and Gynecology, School of Medicine, University of Valencia, Avenida Blasco, Spain

${ }^{4}$ Department of Assisted Reproduction, School of Medicine University of Valencia, Avenida Blasco, Spain

${ }^{5}$ Department of Obstetrics and Gynecology, School of Medicine Federal University of Bahia, Brazil

${ }^{6}$ Department of Obstetrics and Gynecology, School of Medicine Valencia, Spain

Corresponding Author: Fernando Bonilla-Musoles, Professor and Chairman, Department of Obstetrics and Gynecology, University of Valencia, School of Medicine, Avenida Blasco, Ibañez 17-46010 Valencia, Spain, e-mail: profesorbonillamusoles@hotmail.com
In order to increase image quality, in recent years a series of software has been introduced, but with scarce application possibilities and in limited areas.

The most recent and promising is HDlive which incorporates a movable virtual adjustable light source which, as it penetrates, produces selective illumination with respective shadows that result from the structures where light is reflected. This combination of lights and shadows results in spectacular images which are much more real than those obtained with conventional 3D US.

During the past year, we have examined dozens of images generated by 2D/3D US of benign and malignant ovarian and endometrial tumors usign 3D HDlive imaging (E8, GE ${ }^{\circledR}$ Medical System, Kretz, Zipf Austria).

HDlive images were obtained using a special software that calculates light propagation through surface structures in relation to light direction. The transducer uses a second generation dynamic rendering rotor and calculates the data obtained in a graphic processing unit with a power that is twenty times superior to the ones currently in use.

Based on specific case reports of gynecological tumors, we are showing the improvement in image quality using this new software.

This brief article complete the previously and recently published about obstetrics, reproduction and IUDs in this journal.

\section{UTERUS}

The uterine and endometrial morphology (Fig. 1) can be examined as well as with 2D or 3D US, but the quality of the obtained images is clearly superior if 3D US is used.

Normal and all types of müllerian malformations can be depicted 2D/3D US scans can be employed for the diagnosis of the endometrial receptivity in cases of follicular development, ovarian stimulation and IVF-ET (i.e. failure of receptivity).

Other US modes (AVC, VOCAL, 'shell' and double shell techniques) are helpful for uterine measurements, volume calculation and perfect differentiation between myometrium and endometrium (Fig. 2).

\section{ENDOMETRIAL PATHOLOGIES}

Endometrial pathologies as polyps, mucometra (Fig. 3), endometrial hyperplasia and malignancy can be diagnosed with better image quality. 

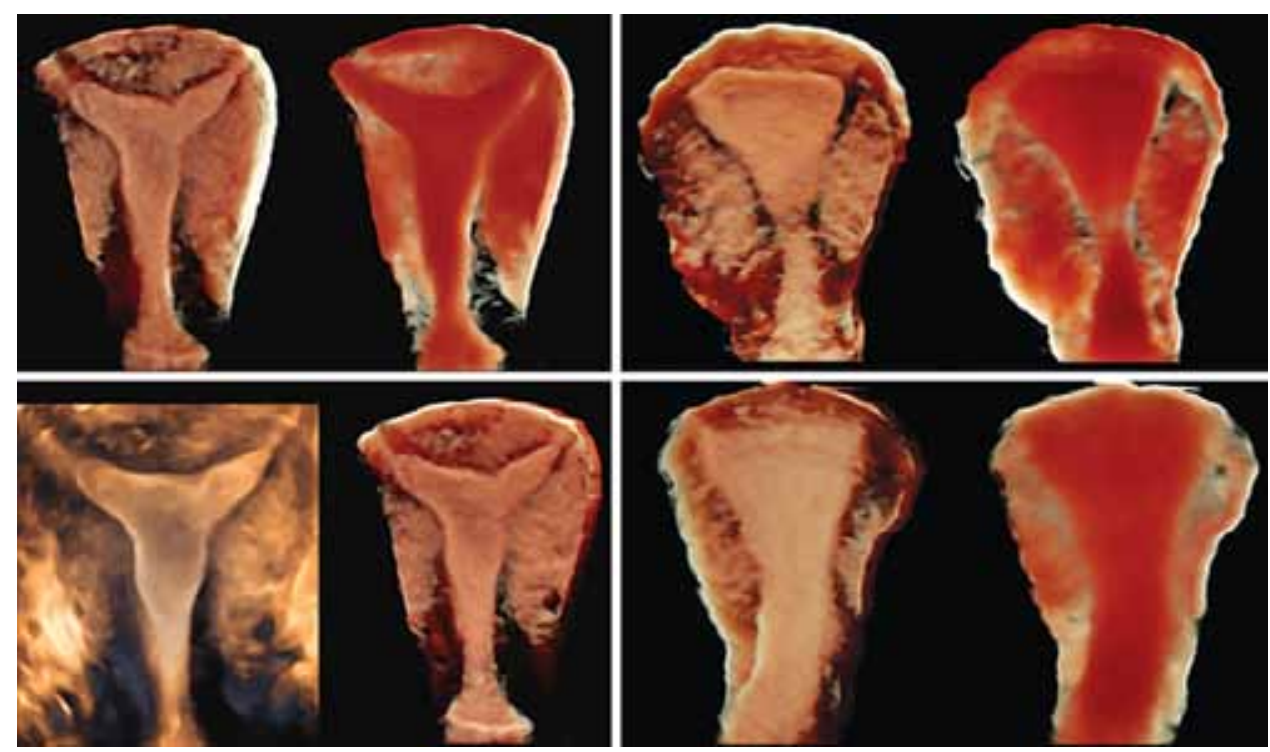

Fig. 1: The uterus (to the left). Normal uterine morphology. Infantile uterus with T endometrial shape. Comparison of 3D (below left) with HDlive. Virtual light entering through different angles and with maximal transparency (above right). It results evident that image quality is much better even when compared with conventional 3D US. The endometrium (to the right). The picture shows the endometrial morphology and homogeneity in the proliferative (above) and secretory hormonal phase (below). The picture shows myometrial and endometrial views in different light angles and maximal luminescence
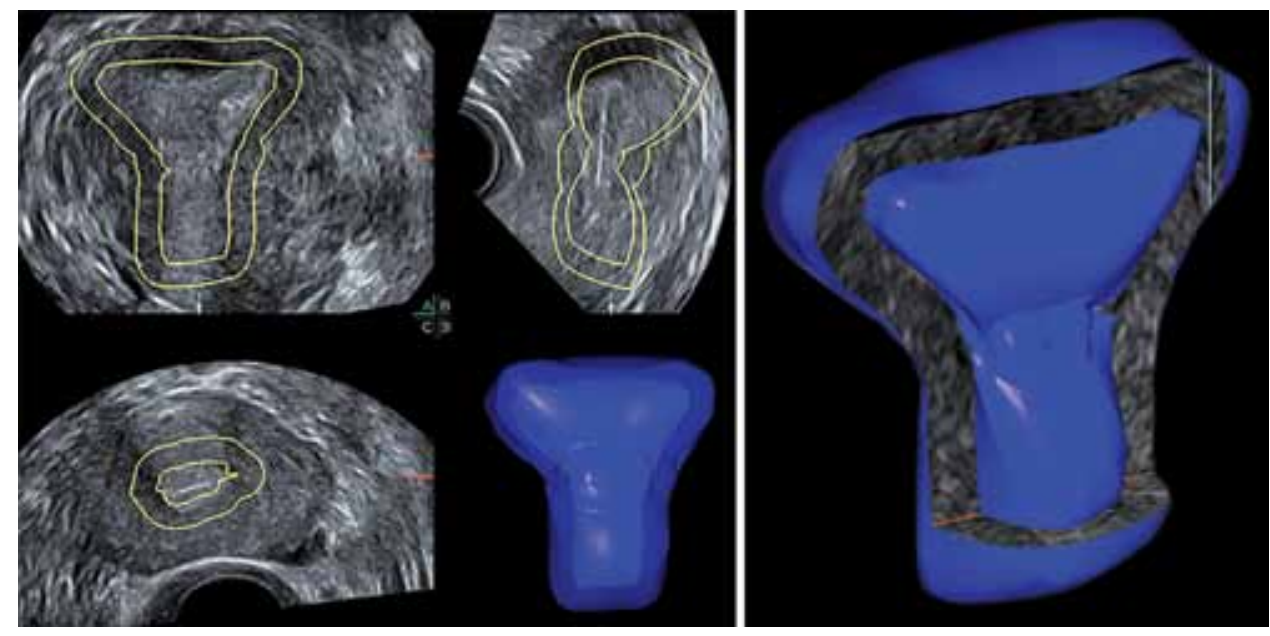

Fig. 2: Limits between myometrium and endometrium 'shell mode' of a normal uterus with the calculated volume of the endometrium and the myometrium. The image shows endometrium (in blue) and myometrium (in gray)

\section{HYPERPLASIA AND CANCER}

The ultrasonographic identification of these pathologies is of the outmost interest especially in postmenopausal patients. It is widely accepted that an endometrial thickness $<5 \mathrm{~mm}$ in asymptomatic postmenopausal patients' rules out the presence of a carcinoma with a $97 \%$ sensibility. In our opinion, it is important to evaluate not only the endometrial thickness, but also its homogeneity, the delimitation of the outer borders and the presence of intramyometrium vessels. There are some varieties of endometrial hyperplasia (benign in origin) which should be differentiated from carcinomas.

The atrophic cystic glandular hyperplasia (Figs 4 and 5) is mainly observed in advanced age patients, its endometrial appearance (thickness, irregular delimitation, solid/cystic endometrial findings) is produced by the cystic dilation of the scarce endometrial glands; due to these ultrasonographic and demographic features a differential diagnosis with carcinoma must be performed. HDlive and Doppler techniques may add diagnostic accuracy in order to differentiate these pathologies.

\section{CANCER}

Endometrial cancer is considered the most frequent neoplasia in developed countries in recent years. The ultrasonographic evaluation of this pathology must take into account the following considerations:

- An early detection screening in asymptomatic patients by using the endometrial thickness cut-off $\leq 5 \mathrm{~mm}$ has a sensibility of 98 to $99 \%$ and it is widely accepted (still some authors consider 3 to $4 \mathrm{~mm}$ as the most appropriate cut-off limit). 

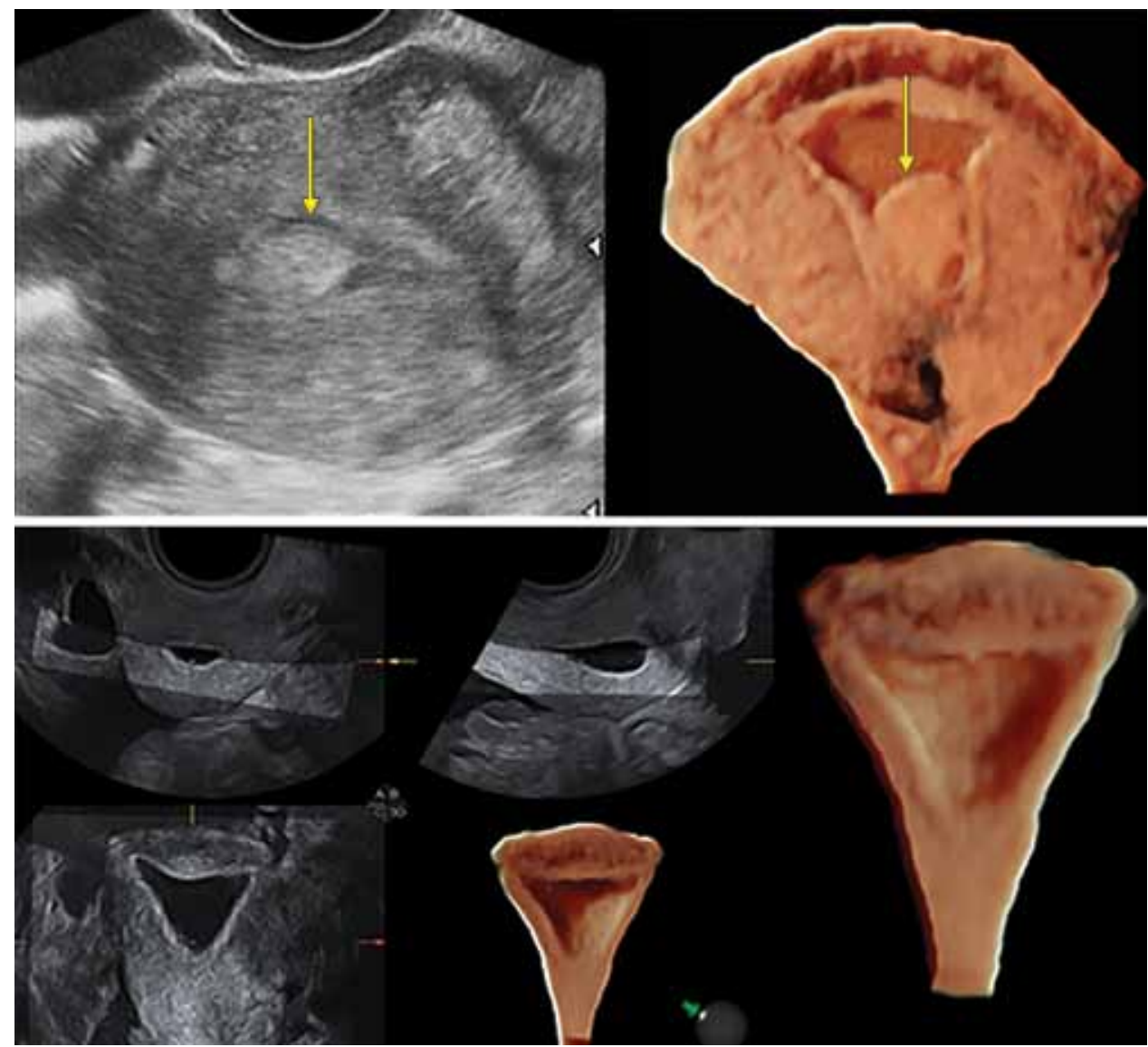

Fig. 3: Comparison of a polyp observed with 2D and 3D HDlive (above). Mucometra. The uterine cavity is filled with mucus. The whole endometrial cavity can be visualized (below)

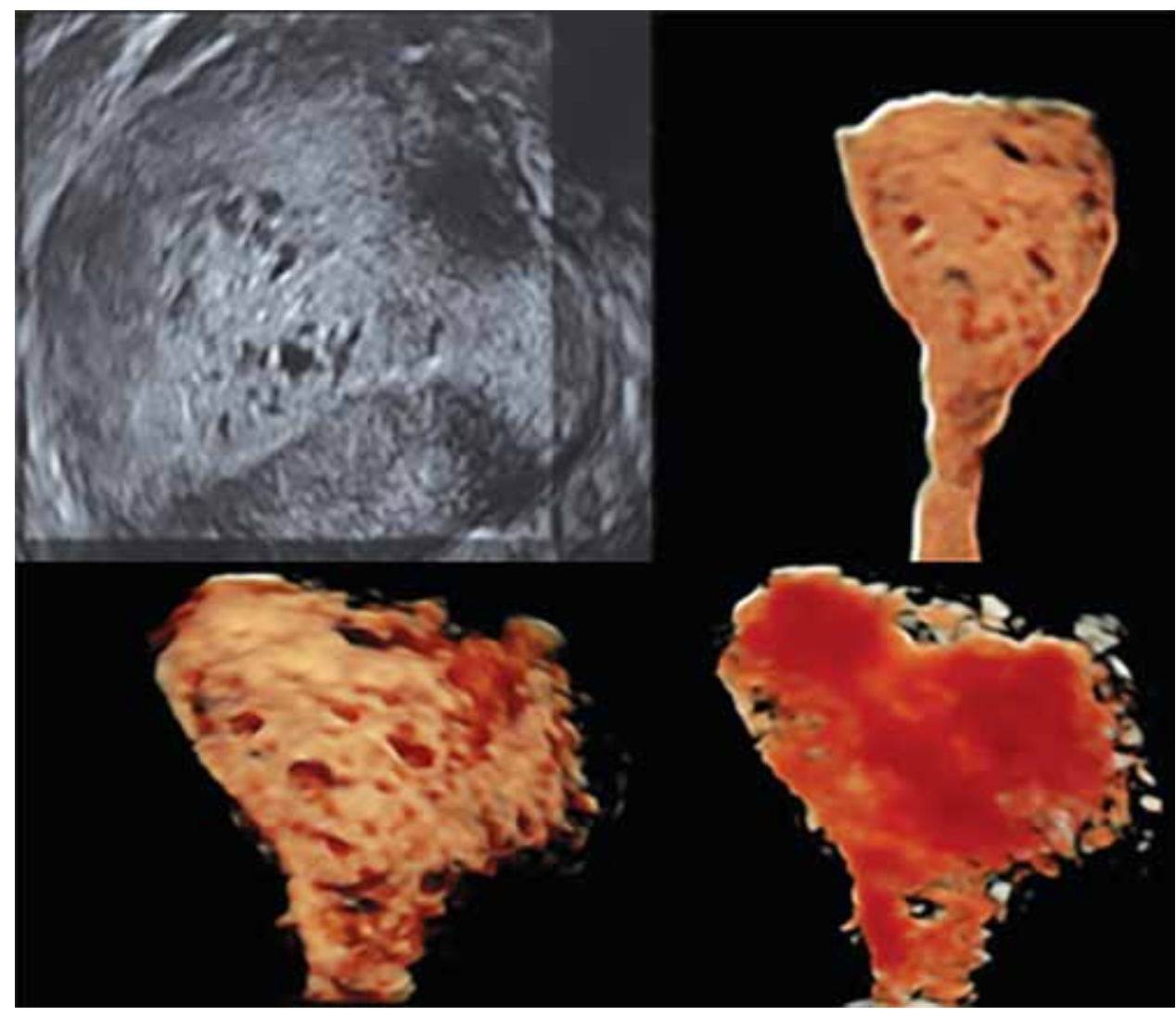

Fig. 4: Atrophic glandular cystic hyperplasia in a 72 years old woman showed in 2D (above left) and HDLive. The whole endometrium is shown using the magic cut system which eliminates the myometrium. The cystic glands appear clearly depicted. The endometrium with its small cysts is also shown using maximal luminescence (below right). The image can be confused with carcinomas 


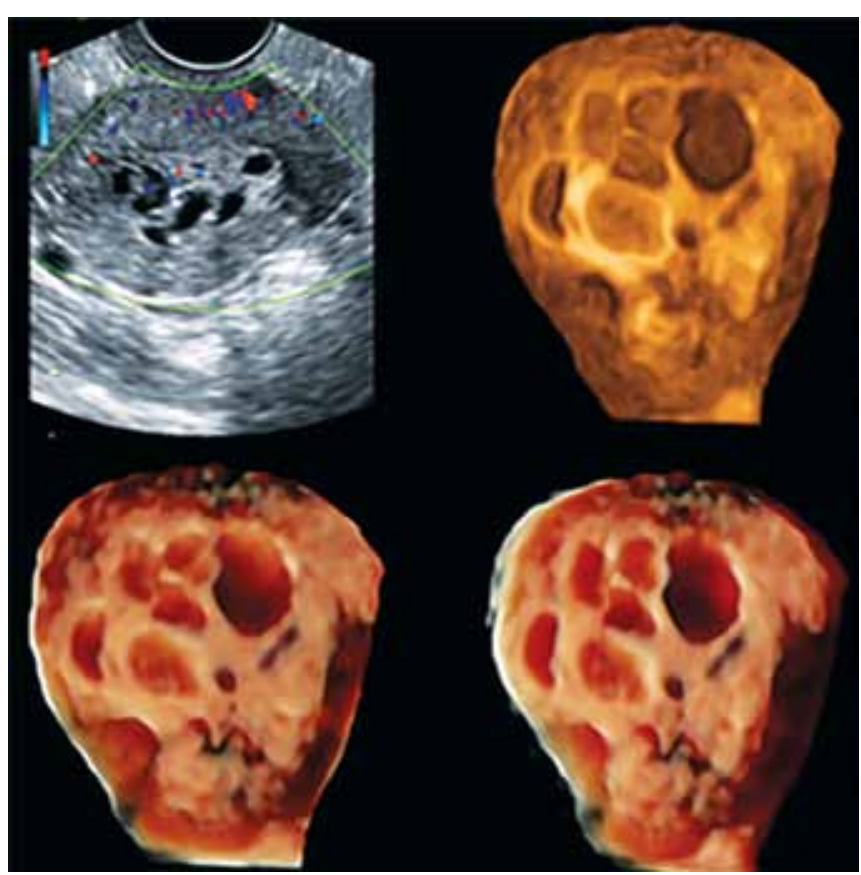

Fig. 5: Atrophic glandular cystic hyperplasia showing multiple cyst of different size. This bizarre image is very suggestive of malignancy

- Myometrial invasion-and also prognosis- constitutes the key feature of FIGO endometrial cancer grading system. Unfortunately, neither 2D nor conventional 3D US had shown any improvement in myometrial invasion evaluation.
Our group is currently evaluating the clinical application of new 3D softwares such as 'shell view' (Fig. 2) of HDlive (Fig. 6) on the study of myometrial invasion in endometrial cancer patients.

The increased quality supposes a better and easier diagnostic potential of, e.g. cases of adenomiosis, miomatosis and müllerian malformations.

\section{FALLOPIAN TUBES}

The most frequent tube pathologies are salpingitis and its chronicle consequence the hidrosalpinx (Fig. 7). Other tumors and cancer are very infrequent.

Acute salpingitis, especially if it contains pus, appears as a pelvic inflammatory disease with numerous irregular cysts of different sizes and forms containing a gray content.

Chronic adnexitis, sactosalpinx and hidrosalpinx, appears as pure cysts of different forms and sizes always econegative and located around the ovaries or behind the uterus.

In many cases, as the present images (Fig. 8), the tubal walls are thickened.

\section{ADNEXAL TUMORS}

Pure ovarian cysts, endometriomas (Fig. 9) and teratomas (see chapter on ovarian teratomas) are the most common benign ovarian tumors.

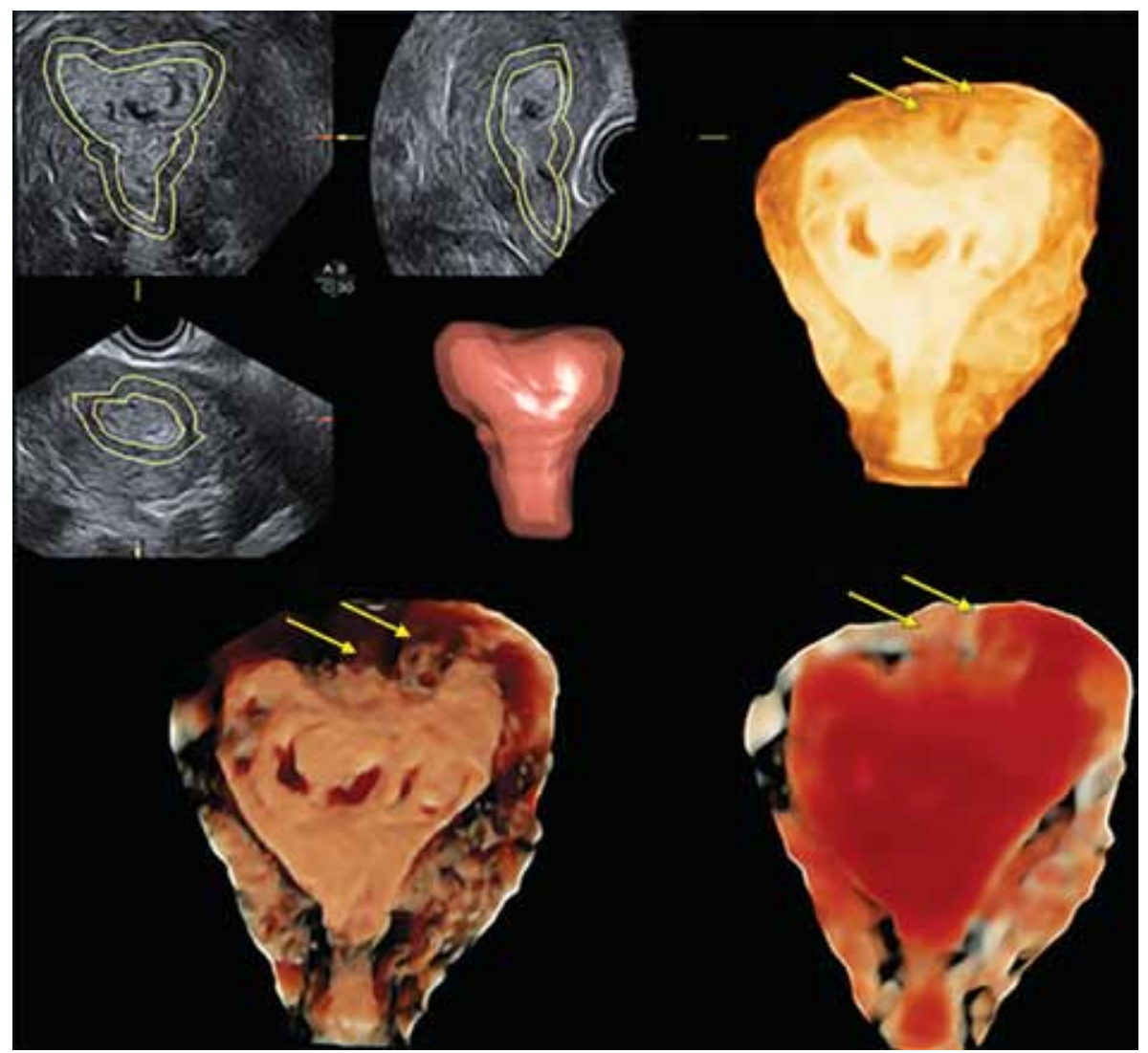

Fig. 6: An adenocarcinoma is showing using the orthogonal planes and shell mode (above and to the left), 3D US (above right) and HDlive (below). The myometrium in the uterine fundus is partially invaded by tumor (yellow arrows) 


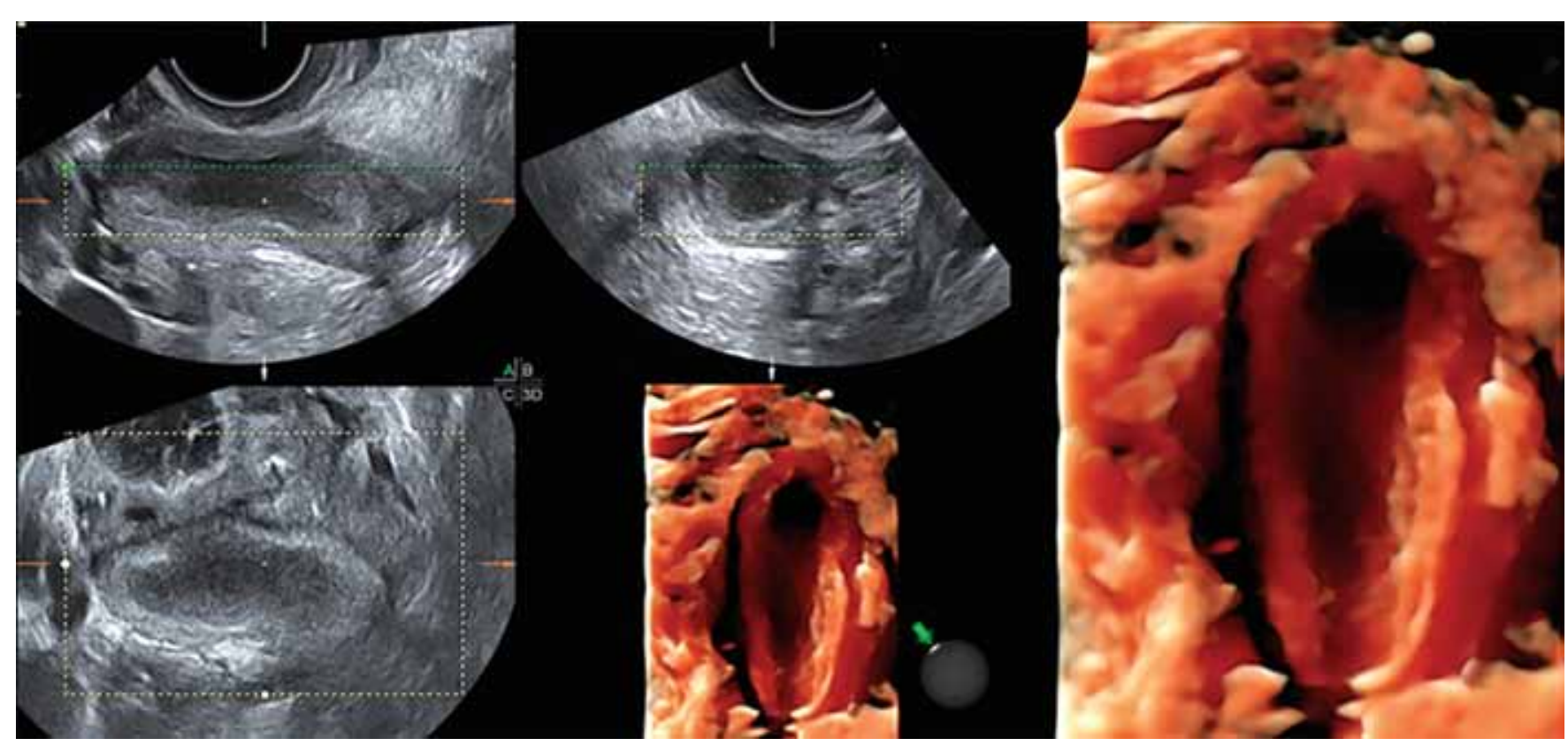

Fig. 7: Two-dimensional orthogonal view and HDlive depicting a distended fallopian tube sequelae of a chronic salpingitis. HDlive clearly shows the thickened wall dilated tube and its econegative content (also known as sactosalpinx). There is no septums or papillae, but it is not unfrequent to observe them as a consequence of inflammation of the mucosa folds

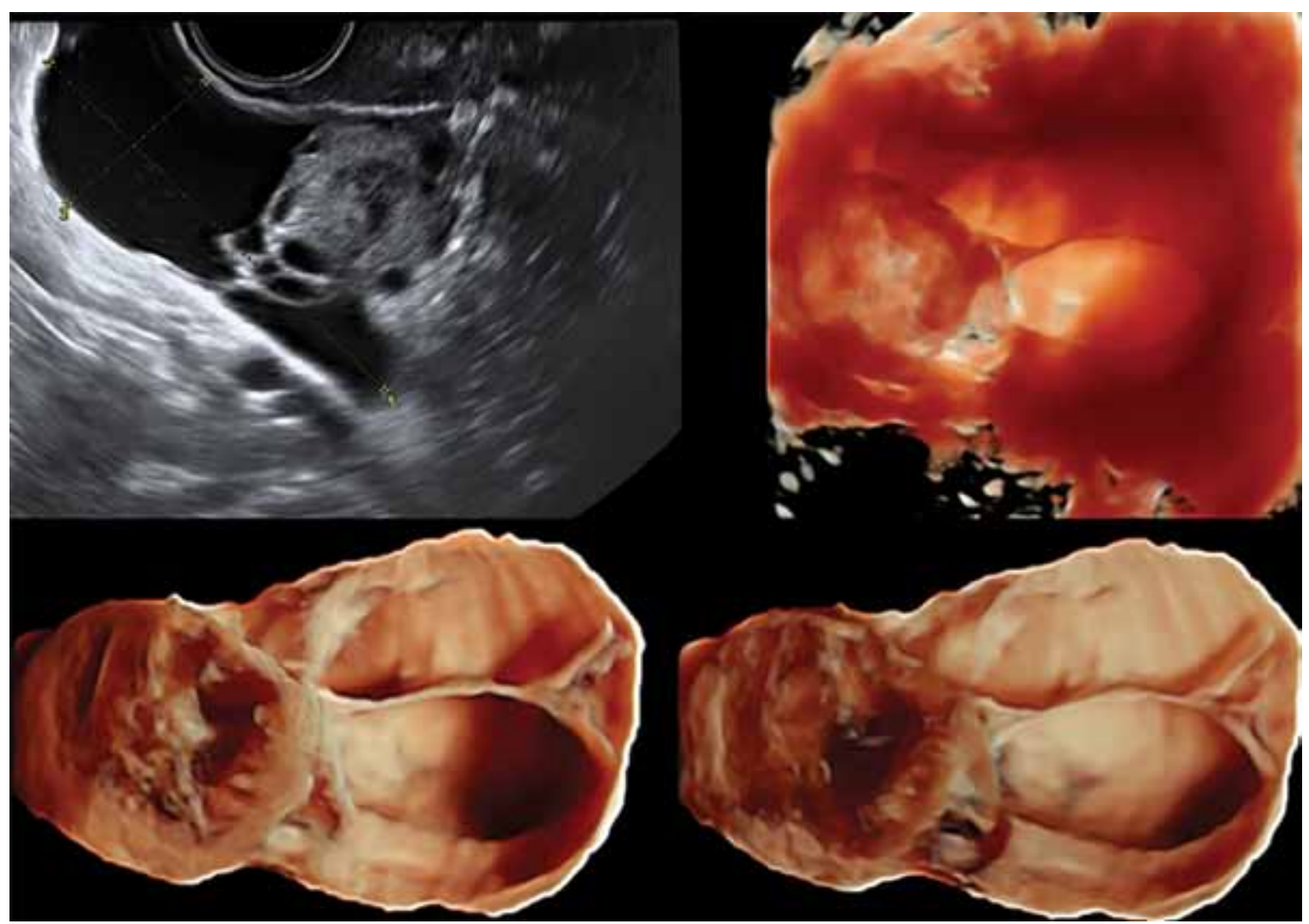

Fig. 8: Chronic salpingitis. Remain only from the old inflammatory process, the presence of tube dilatations called 'sactosalpinx'

Pure cysts arise normally from the celomic epithelium of the ovarian surface, called epithelium germinalis, which give riseto $85 \%$ of all ovarian tumors (the so-called cystoadenomas and cystocarcinomas).

They are characterized by a unique, round, well delimited, and with homogeneous inner cyst surface (Fig. 10).
Endometriomas are the consequence of retrograde menstruation and endometrial cell implantation in the ovarial surface, and many other places (Fig. 9). Its pathognomonic ecographic appearance is a cystic wall containing a homogenous-gray echo, the differential diagnosis must be done with infected cysts or dermoid tumors. 


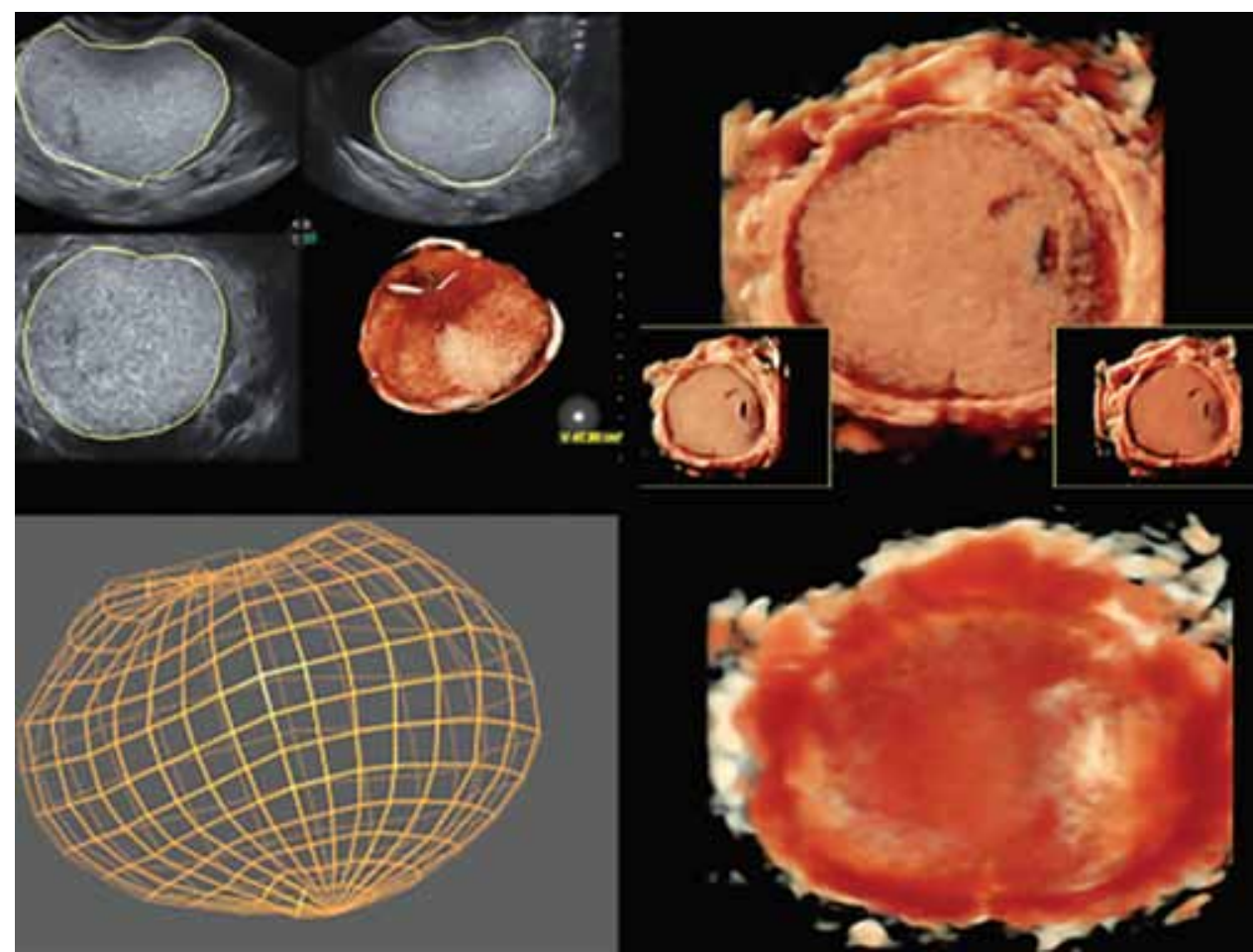

Fig. 9: Typical ovarian endometrioma examined with 2D and 3Dlive using maximal translucency (below right). Also, its volume has been calculated using the vocal mode (below left)
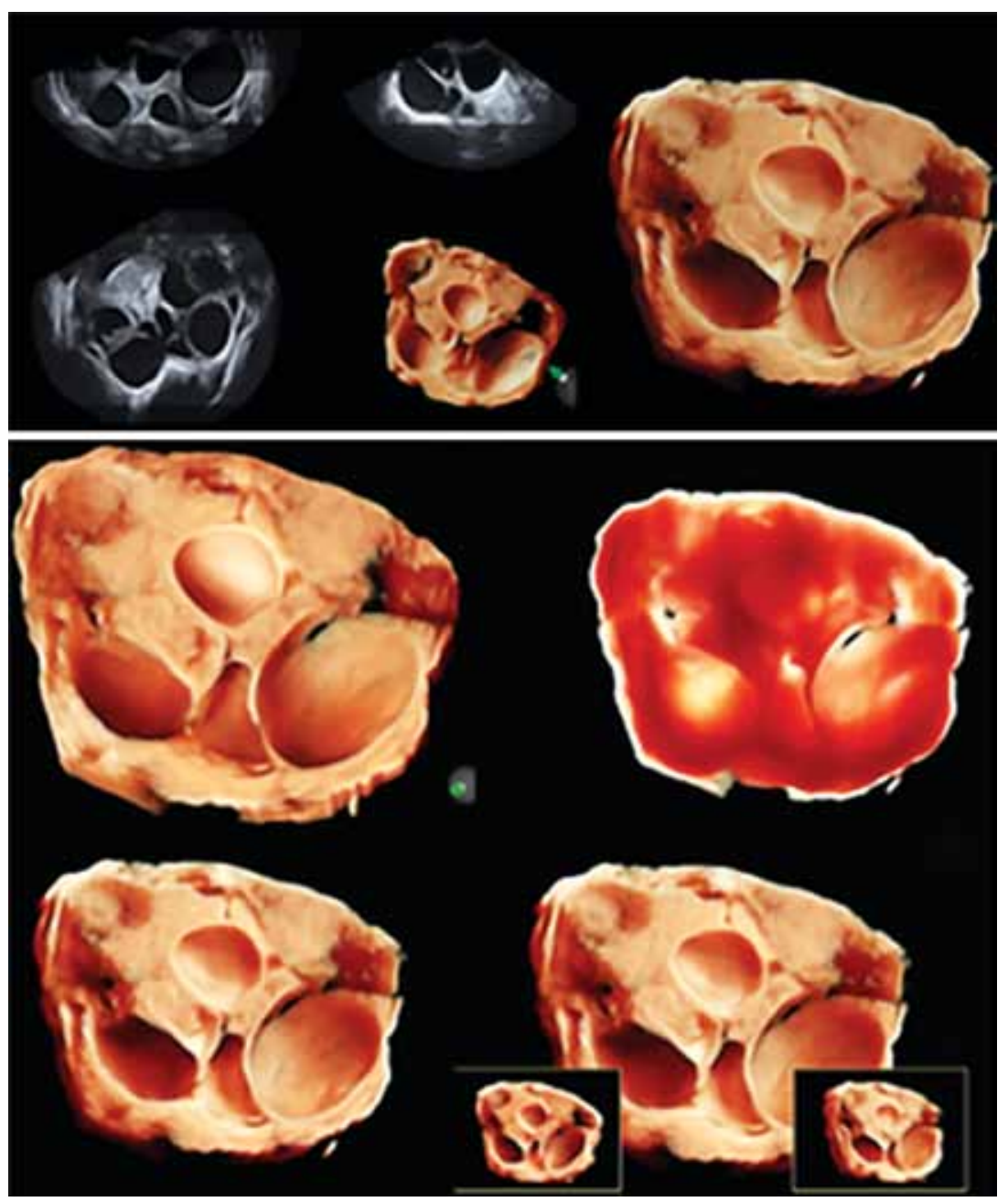

Fig. 10: Ovarian serous cystoadenoma with multicystic component. HDlive allows the study in several ecographic views. Note the high-definition image of the inner surface of the cysts. Translucency view is shown in the upper right image 


\section{MULTICYSTIC OVARIAN TUMORS}

Although many of these are benign tumors, a careful examination is mandatory in order to rule out malignant features.

- The inner zone: must be 'pure' cysts without internal echoes

- The shape, size and thickness of the septums: must be homogeneous and smooth septums free of endophitic papillae.

- Absence of papillae, typically seen in malignancy

- Other features of malignancy: ascitis, exophitic tumors, metastasis, etc.

Besides having a low incidence, its big mortality rates makes it the worst cancer in female. HDlive may help to increase the diagnostic accuracy. Herein, we show three interesting cases (Figs 10 and 11).

\section{Teratomas}

These tumors are derived from the primordial germinal cells which are located on the germinal line starting from the primitive gut primordial ovary on the germinal epithelium. Teratomas are usually located on the sacrocoxis and ovary, and contains full-developed tissues derived from the three germinal layers (ectoderm, mesoderm, and endoderm).

The great majority are benign, however many of them present aggressive behavior and early metastasis.

The ultrasonographic appearance of teratomas are cystic images containing echogenic heterogeneous masses (fat and sebaceous content), and hyperechogenic zones corrresponding to bone tissue.

The following images of a typical case, show a clear visualization of all these structures including teeth, hair, fatty tissue and bones (see article on ovarian teratomas).

\section{Ovarian Cancer}

Neither all solid (or solid/cystic) tumors of ovarian localization are malignant nor persistent. Also, not all the 'anechogenic' cystic masses are benign, exceptionally they may be 'borderline' or malignant tumors.
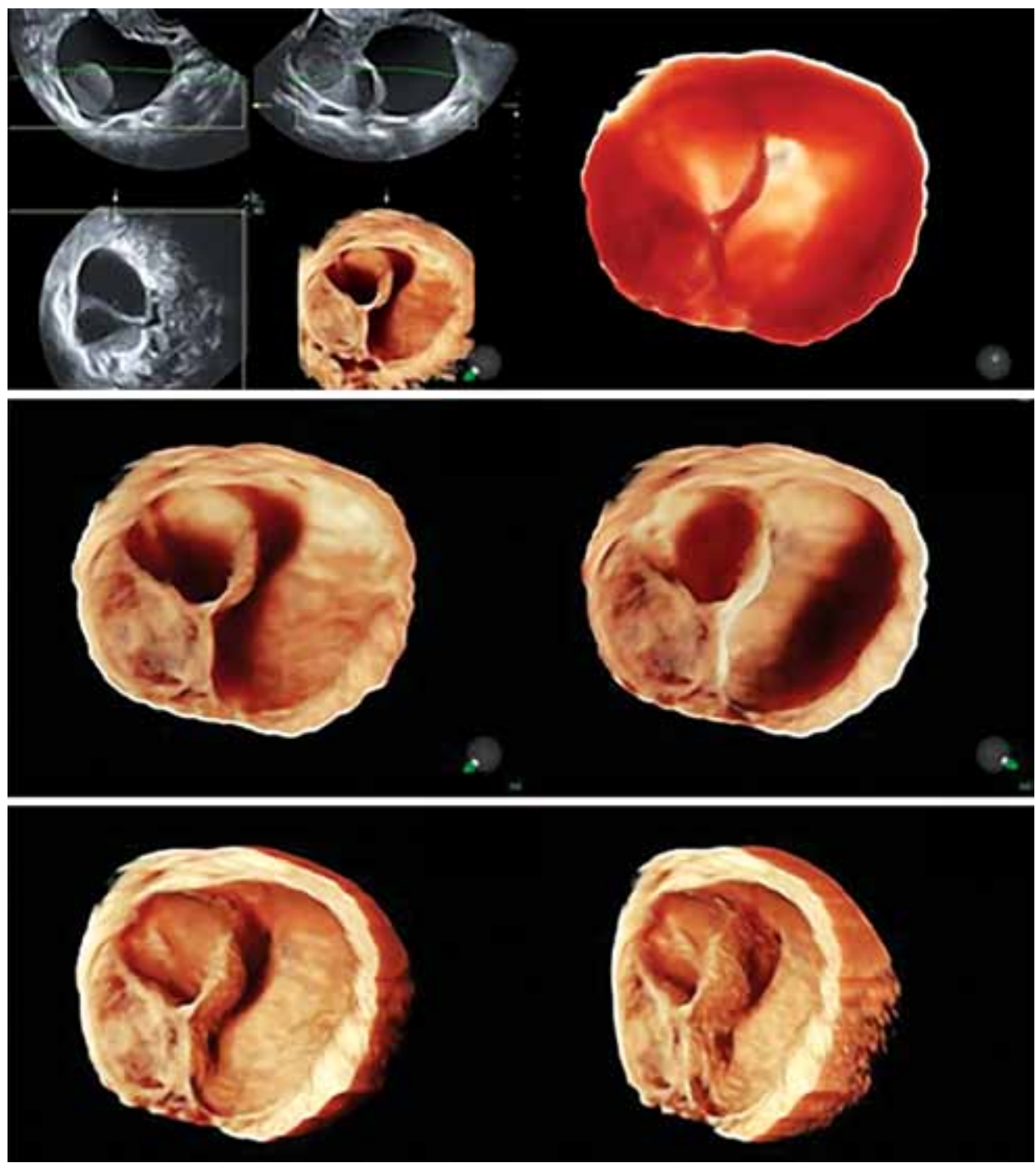

Fig. 11: Typical cyst with walls visualized with HDlive in different light positions and resembling a mixed cyst. However, when HDlive is applied it is concluded that it contains only another small benign cyst 
Over $90 \%$ of malignant ovarian neoplasm show ultrasonographic features able to conclude in a correct diagnosis or at least able to 'alert' the clinician towards a high index of suspicion.

The 'quality' of the ecographic image is of the outmost importance to clarify the diagnosis, especially in atypical cases.

The majority of ovarian cancers are composed from a mixture of solid and solid-cystic parts. Mostly of the irregular cystic components are formed by necrotic cancer tissue (Fig. 12).

\section{DISCUSSION}

Over the years, there have been efforts to improve 2D ultrasound image quality, but except for the switch from abdominal to vaginal route along with higher frequencies introduced during the early 1980s, there has been practically no substantial advances.

In recent years, a series of software has been introduced, but with scarce application possibilities and in limited areas.

These modalities are the inverse mode, which special application for fluid-containing pathologies; the AVC mode (automatic volume calculation) important for antral follicle count and measurement of gynecological tumor volumes; the VOCAL mode (virtual organ semiautomatic volume calculation), which has application in measurement of volumes; the TUI mode (tomographic ultrasound imaging), which obtains serial ultrasound images similar to a computerized axial tomography and HDlive (high definition real time ultrasound).
A correct discrimination between benign and malignant pathology is mandatory for management and prognosis; most women with adnexal masses do not have cancer. ${ }^{1}$ The issue about finding an accurate and simple test for discriminating benign from malignant adnexal tumors has become like the Holy Grail of gynecological ultrasound research., ${ }^{2,3}$ A plethora of diagnostic models have been developed over the last two decades: ${ }^{1}$

- Only ultrasound parameters (Ferrazzi, Finkler, Granberg, Sassone, De Priest, Lerner, Merz, Risk of Malignancy Index (RMI) (see references in 1). ${ }^{2,5}$

- Two-dimensional ultrasound and 3D tumor volume measurement. ${ }^{3,4}$

- Combined with 2D Doppler [Kurjak (see references in 1)], Zannoni ${ }^{6}$ or with 3D Doppler angiography 3D. ${ }^{2}$

- Ultrasound and biomarkers: Ca 125,7,8 Human epididymis secretory protein-4 (HE4) ${ }^{7,8}$

- Ultrasound combined with various prediction models [International Ovarian Tumor Analysis (IOTA)]. ${ }^{2}$

Although all these parameters have been described in clinical practice ${ }^{1,2}$ to the best of our knowledge, the most precise are $\mathrm{RMI}^{5,7}$ and the Mainz University criteria. ${ }^{1}$ However, the perfect marker is still to be defined.

The most recently described IOTA study, combined predictive models and ultrasonographic parameters; for regression model \#1, twelve clinical/ecographic parameters are employed and for regression model \#2, only six demographic and ecographic parameters were used.

Unexpectedly, there was substantial variability in the assessment of various measurements and categorical variables with substantial variability in the calculation of the malignancy risk. ${ }^{4}$
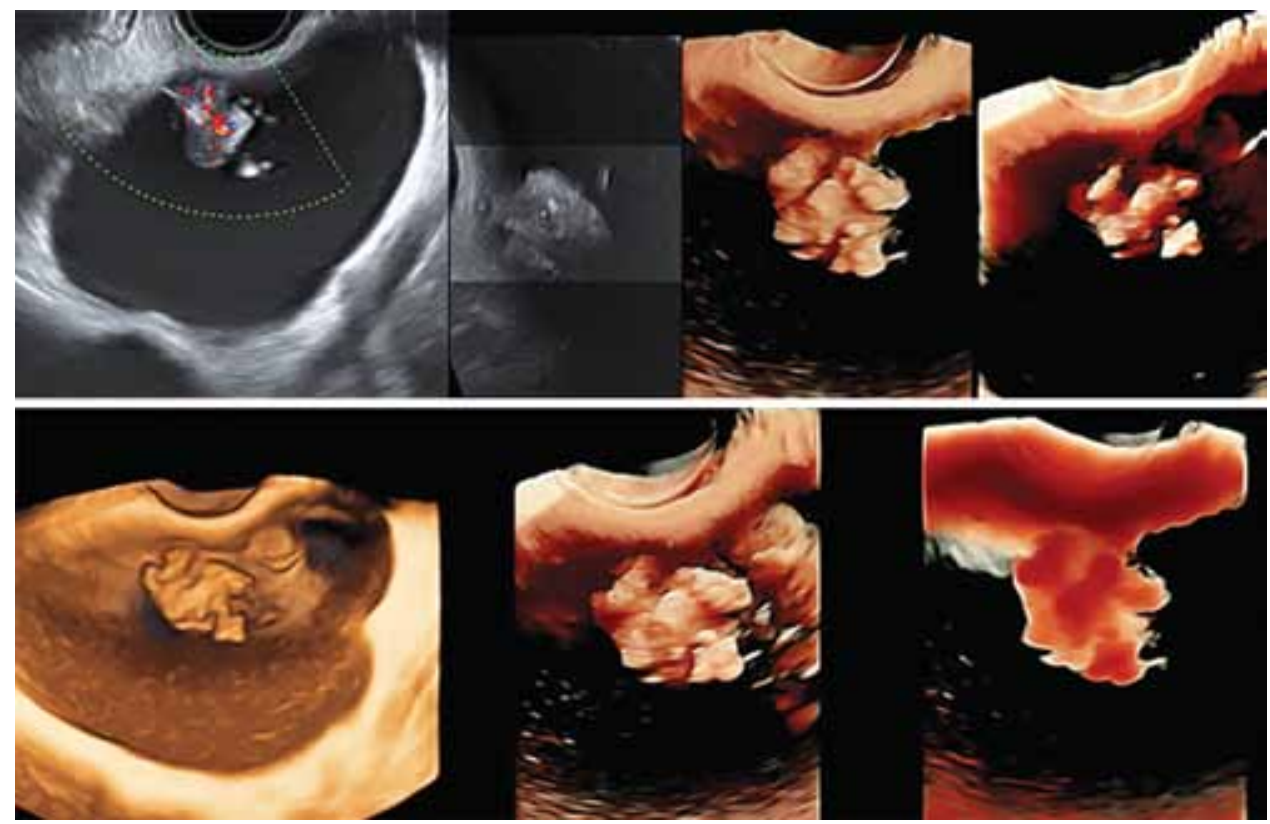

Fig. 12: Ovarian cyst showing a small vascularized papillae visualized with $2 \mathrm{D}$, US power Doppler and conventional 3D. The ultrasound images are very suspicious of malignancy (above). The same case studied with HDlive and maximal luminiscence. Observe the wonderful images of the papillary component. Compare 3D (Figure 11) with HDlive (below) 
Nevertheless, none has gained universal acceptance in routine clinical practice, including the recent IOTA system, which showed that the diagnostic models performed well when used by experimented sonographers.

The agreement between operators was much better when they tried to determine the nature of adnexal tumors based on subjective assessment of ultrasound findings. ${ }^{3}$

Subjective assessment of ultrasound images by experienced clinicians is the best way to characterize ovarian and endometrial pathology. Many endometrial and adnexal masses have a typical ultrasound appearance and will be correctly classified as benign or malignant. ${ }^{2,9}$ Figure 10 is a clear example.

Many studies have addressed the relationship of the endometrial thickness and malignancy risk. It is generally accepted that below $3 \mathrm{~mm}$ there is no estrogenic effect or malignancy risk; and below $5 \mathrm{~mm}$ the malignancy risk is almost negligible. However, several authors ${ }^{9}$ have described case reports of adenocarcinomas (almost always Müllerian in origin) with endometrial thickness below $3 \mathrm{~mm}$.

In order to enhance diagnostic sensibility, some parameters were progressively introduced are as follows:

- The evaluation of the homogeneity

- The evaluation of delimitation

- Doppler study of endometrial vascularization

Enhance the US image quality by using new 3D modes (AVC, VOCAL, Angio-Doppler, HDLive, etc.) is mandatory when a diagnosis consensus in endometrial malignancy is pretended. ${ }^{9}$

Summarizing, US knowledge and the better image quality are the best parameters to determine the benign or malignant nature. In this way, HDlive, by increasing image quality, offers new possibilities of extremely interest (Figs 8 to 11).

Recent publications, most of them focused in obstetrics, show that HDlive provides a much more natural and realistic appearance of the normal embryo, $10,11,13,14,22,24$ fetuses, $10,11,13-16,22,23$ their facial expressions, $11,13,15,16,22,24,25,34$ cases of fetal abnormalities: acrania/exencephaly, $11,13,22,25$ cyclopia with proboscis; ${ }^{27}$ cystic hygroma, ${ }^{22,26}$ Omphalocele; ${ }^{11,13,14,22}$ multicystic kidney; ${ }^{18}$ persistent cloaca, ${ }^{28}$ siamese twins, ${ }^{20}$ TRAP syndrome ${ }^{29}$ and umbilical vein varix..$^{30}$

The most recent articles have been focused in visualizing special organs as heart, ${ }^{31,32}$ the uvula and the soft palate $^{33}$ and yolk sac. ${ }^{35}$

Pictures obtained were so beautiful that five of these images showed in the articles were selected as pictures of the 'month'. '12,15-17,20

Some other articles also show pictures of borderline ${ }^{12}$ and malignant ovarian tumors ${ }^{11,21}$ as well as endometrial pathology, showing the usefulness of this new technology in the gynecological field.

In assisted reproduction HDlive provided improved visualization of the growing follicle and its content (follicular fluid, cumulus oophorus), polycystic ovaries and hyperstimulation ovarian appearance. ${ }^{17,19}$

The present article shows images of uterine and ovarian tumors. The images, apart from being beautiful and of much better quality, may be useful in helping patients to understand such processes, and may enhance patient knowledge about their disease and also increase patientphysician communication.

HDlive use in obstetrics and gynecology by adding the combination of light and shadows results in spectacular, natural resembling; photo-like images that are much more realistic than the ones obtained using conventional 3D US.

This novel technology deserves further evaluation in clinical obstetrics and gynecological practice.

\section{REFERENCES}

1. Bonilla-Musoles F, Raga F, Vergara F, Alvarez JC, Machado LE, Blanes J, Bailao LA, Osborne N, Bonilla Jr F. El ovario (V). Tumores malignos. La ecografía. In: Bonilla-Musoles F. Ecografia vaginal. Doppler y tridimensión. Panamericana Ed. Madrid 2000;485-524.

2. Kaijser J, Bourne T, Valentin L, Sayasneh A, Van Holsbeke C, Vergote J, Testa C, Franchi D, Van Claster B, Timmerman D. Improving strategies for diagnosing ovarian cáncer: A summary of the International Ovarian Tumor Analysis (IOTA) studies. Ultrasound Obstet Gynecol 2013;41(1):9-20.

3. Jurkovic D. Referee Commentaries: Intra-and interobserver agreement when describing adnexal masses using the International Ovarian Tumor Analysis terms and definitions: A study on three-dimensional ultrasound volumes. Ultrasound Obstet Gynecol 2013;41(3):245-246.

4. Sladkevicius $P$, Valentin L. Intra-and interobserver agreement when describing adnexal masses using the International Ovarian Tumor Analysis terms and definitions: a study on three-dimensional ultrasound volumes. Ultrasound Obstet Gynecol 2013;41(3):318-327.

5. Valentin L, Ameye L, Savelli L, Fruscio R, Leone FPG, Czekierdowski A, Lissoni AA, Fischerova D, Guerriero S, Van Holsbeke C, Van Huffel S, Timmerman D: Unilocular adnexal cysts with papillary projections but no other solid components: is there a diagnostic method that can classify them reliable as benign or malignant before surgery? Ultrasound Obstet Gynecol 2013;41(5):570-581.

6. Zannoni L, Savelli L, Jokubkiene L, Di Legge A, Condous G, Testa AC, Sladkevicius P, Valentin L. Intra-and interobserver reproducibility of assessment of Doppler ultrasound findings in adnexal masses. Ultrasound Obstet Gynecol 2013;41(1):93-1001.

7. Jacobs I, Oram D, Fairbanks J, Turner J, Frost C, Grudzinskas JG. A risk of malignancy index incorporating CA 125, ultrasound and menopausal status for the accurate preoperative diagnosis of ovarian cancer. Brit J Obstet Gynaecol 1990;97:922-929. 
8. Moore Rg, Brown AK, Miller MC, Skates S, Allard WJ, Verch T, Steinhoff M, Messerlian G, Di Silvestro P, Granai CO, Bast RC Jr. The use of multiple novel tumor biomarkers for the detection of ovarian carcinoma in patients with a pelvic mass. Gynecol Oncol 2008;108(2):402-408.

9. Bonilla-Musoles F, Vergara F, Blanes J, Osborne N, Raga F, Bailao LA, Alvarez Bonilla Jr F, Machado LE, Casañ E. El endometrio (II). Procesos inflamatorios; procesos tumorales benignos y malignos. In: Bonilla-Musoles F. Ecografia vaginal, Doppler y tridimensión. Panamericana Ed. Madrid 2000;1:337-366.

10. Bonilla-Musoles F, Raga F, Castillo JC, Bonilla Jr. F, Climent MT, Caballero O. High definition real time ultrasound (HDlive) of embryonic and fetal malformations before week 16. Donald School J Ultrasound Obstet Gynecol 2012;7:1-8.

11. Bonilla-Musoles F, Raga F, Osborne N, Bonilla Jr. F, Castillo JC, Caballero O. Pictorial review. Multimodality 3D volumetric ultrasound in Obstetrics and Gynecology with emphasis on HDlive technique. Ultrasound Quarterly 2012;7:1-8.

12. Grigore M. HDlive imaging of a serous borderline ovarian tumor. Ultrasound Obstet Gynecol 2013;41(5):598-599.

13. Hata T, Hanaoka U, Tenkumo C, Sato M, Tanaka H, Ishimura $\mathrm{M}$. Three- and four-dimensional HDlive rendering images of normal and abnormal fetuses: pictorial essay. Arch Gynecol Obstet 2012;286(8):1431-1435.

14. Hata T, Tenkumo C, Sato M, Kanenishi K, Ishimura M. Three dimensional HDlive-rendered images of intrauterine abnormalities during pregnancy. J Med Ultrasonics 2013; 40(2):179-180.

15. Kagan KO, Pintoffl K, Hoopmann M. First-trimester ultrasound images using HDlive. Ultrasound Obstet Gynecol 2011;38(5):607-608.

16. Merz E. OberflächendarstellungeinesFeten $(28+2$ SSW $)$ mittelsHDliveTechnologie. UltraschallMed 2012;33(3):211-212.

17. Raga F, Bonilla Jr F, Castillo JC, Bonilla-Musoles F. HDlive ultrasound images in ART. RBM Online 2013;26:269-271.

18. Tanaka T, Ito M, Uketa E, Mori N, Hanaoka U, Kanenishi K, Tanaka H, Hata T. Antenatal three-dimensional sonographic features of multicystic kidney. J MedUltrasonics 2013;40(2):181-183.

19. Bonilla-Musoles F, Caballero O, Osborne N, Raga F, Bonilla Jr F, Castillo J. Technical Note HDlive 3D Ultrasound and follicular development. J Med Ultrasonics 2013;40(3):315-319.

20. Merz E. 3D-Darstellung von siamesichenZwillingenmit 12+3 Schwangerschaftwochen. Ultraschall Med 2013;34(2):109-119.

21. Hata T, Kanenishi K, Mashima M, Nitta E, Mori N, Hanaoka $\mathrm{U}$, Tanaka H. HDlive rendering image of adnexal tumors: preliminary report. J Med Ultrasonics 2013. DOI: 10.1007/ s10396-013-0489-5.
22. Bonilla-Musoles F, Raga F, Castillo JC, Bonilla FJr, Climent MT, Caballero O. High definition real-time ultrasound (HDlive) of embryonic and fetal malformations before week 16. Donald School J Ultrasound Obstet Gynecol 2013;7:1-8.

23. Hata $T$, Hanaoka $U$, Masato Mashima, Ishimura M, Marumo G, Kanenishi K, Four-dimensional HDlive rendering image of fetal facial expression: A pictorial assay. J Med Ultrasonics 2013.40:437-441.

24. Hata T. HDlive rendering image at 6 weeks of gestation. J Med Ultrasonics 2013. DOI: 10.1007/s10396-013-0450-7.

25. Hata T, Uketa E, Tenkumo C, Hanaoka U, Kanenishi K, Tanaka H. Three- and four-dimensional HDlive rendering image of fetal acrania/exencephaly in early pregnancy. J Med Ultrasonics 2013;40(1):271-273.

26. Hata T, Hanaoka U, Tenkumo C, Ito M, Uketa E, Mori N, Kanenishi K, Tanaka H, Ishimura M. Three-dimensional HDlive rendering image of cystic hygroma. J Med Ultrasonics 2013;40:297-9 (IF = 0.635)

27. Hata T, Hanaoka U, Mashima M. HDlive rendering image of cyclopia and a proboscis in a fetus with normal chromosomes at 32 weeks of gestation. J Med Ultrasonics 2013.doi: 10.1007/ s10396-013-0466-z.

28. Ishibashi M, Tanaka H, Ito M, Uketa E, Mori N, Hanaoka U, Kanenishi K, Hata T. Antenatal three-dimensional sonographic diagnosis of persistent cloaca. J Med Ultrasonics 2013;40:275-277.

29. Tenkumo C, Tanaka H, Ito M, Uketa E, Mori N, Hanaoka U, Kanenishi K, Ando M, Hata T. Three-dimensional HDlive rendering images of the TRAP sequence in the first trimester: Reverse end-diastolic umbilical artery velocity in a pump twin with an adverse pregnancy outcome. J Med Ultrasonics 2013;40:293-296.

30. Kanenishi K, Nitta E, Mashima M, Hanaoka U, Koyano $\mathrm{K}$, Tanaka H, Hata T. HDlive imaging of intra-amniotic umbilical vein varix with thrombosis. Placenta (2013), http:// dx.doi.org/10.1016/j.placenta.2013.08.008

31. Hata T, Mashima M, Ito M, Uketa E, Mori N, Ishimura M. Three-dimensional HDlive rendering images of the fetal heart. Ultrasound Med Biol 2013;39:1513-1517.

32. Grisolia G, Tonni G. Fetal echocardiography using HDlive. J Obstet Gynecol Canada 2013;35:497-499.

33. Tonni G, Grisolia G. Fetal uvula: navigating and lightening the soft palate using HDlive. Arch Gynecol Obstet 2013 Aug;288(2):239-244.

34. Grigore M, Mareş A. The role of HDlive technology in improving the quality of obstetrical images. Med Ultrason 2013;15:209-214.

35. Hata T. HDlive rendering image at 6 weeks of gestation. J Med Ultrasonics 2013;40:495-496. 